\title{
A Comparative Study of Language Development in Monolingual and Bilingual Children with Autism Spectrum Disorders
}

\author{
Mohammad Hamad Al-khresheh ${ }^{1}$ \\ ${ }^{1}$ Department of English Language, Faculty of Arts and Sciences, Northern Border University, Arar, Saudi Arabia \\ Correspondence: Mohammad Hamad Al-khresheh, Department of English Language, Faculty of Arts and \\ Sciences, Northern Border University, Arar, Saudi Arabia. E-mail: mohd_khresheh@yahoo.com
}

\author{
Received: July 11, $2020 \quad$ Accepted: August 14, $2020 \quad$ Online Published: August 25, 2020 \\ doi:10.5539/ijel.v10n6p104 URL: https://doi.org/10.5539/ijel.v10n6p104
}

\begin{abstract}
This study sought to analyze how the process of language development differed between a group of monolingual and bilingual children with autism spectrum disorders $(n=201)$ who were aged between $5-8$ years and hailed from different countries around the world. To achieve this objective, a self-designed five-point Likert scale covering six different language domains was developed to measure the level of difficulty experienced by the participants. The measurement of the level of these difficulties was conducted based on reliable statistical analysis methods. The participants in the two groups were then compared on the basis of these difficulties. No statistically significant differences between the two groups were observed in any language domain. While mild differences within the items of main domains were indeed observed, they were deemed to be statistically non-significant. The results of this study suggest that both monolingualism and bilingualism do not have any detrimental effects on the language development abilities of children with autism spectrum disorders. Both groups were observed to experience the same level of difficulty in their language development process. This study's limitations, implications, and other research suggestions have been discussed in detail as well.
\end{abstract}

Keywords: autism spectrum disorders, language development, monolingualism, bilingualism

\section{Introduction}

Autism spectrum disorder (ASD) happens to be a highly multifarious disorder observed in children. It causes numerous roadblocks in the overall development of a child in different areas like social skills, communication, speech, and behaviors. As per the Diagnostic and Statistical Manual, this condition is formally defined as an observable deficiency in one's social interaction and communication abilities across a wide range of contexts. Autism has also been characterized as a spectrum disorder since it results in children having to face a combination of distressing challenges in the development of their social patterns, social skills, communication, which results in restricted behavioral abilities (Vahia, 2013).

As per a survey conducted in the United States, 1 in 54 children suffers from ASD (Maenner et al., 2020). It is considered to be a result of several environmental and genetic factors. Since the disorder affects different children differently, it prevents them from gaining proficiency in any skills or from pursuing intellectual challenges. It occurs alongside a host of other comorbid disorders as well. ASD can restrict a child's interactions and communication with their social environment and society at large (Posar, Resca, \& Visconti, 2015). The signs of autism tend to be visible right from an early age. Some autistic children may not be able to develop their communication and social abilities further once they begin exhibiting autistic behavior (Sandbank et al., 2017).

A distinct impairment of one's social communication and language abilities happens to be one of autism's primary diagnostic criteria. Likewise, several attention and sensory issues may also combine with core symptoms to worsen the effects of the disorder further. The language development process may be affected negatively by autism, ranging from nonverbal impairment issues to the adoption of an idiosyncratic language, such as echolalia or other unusual tones, which are used by autistic children to communicate with others (Mody \& Belliveau, 2013). ASD is generally comorbid with other intellectual disabilities as well, to the extent that an autistic person with an average Intelligence Quotient (IQ) is considered to be a high-functioning individual despite language impairment issues. Autistic children have receptive and expressive language impairments as well. However, the severity of these impairments may vary widely depending on the developmental level, environment, and age of the child. Autistic children also suffer from delayed or impaired language skills right from their early ages, which is also around the 
time that normal children start learning to form phrases and sentences (Weismer, Lord, \& Esler, 2010). Children with autism may have their language development abilities restricted to varying degrees. For instance, some may not be able to progress beyond basic communication whereas others might possess a comprehensive vocabulary and enjoy mastery over specific topics and subjects. Certain children may be unable to understand or use vocal tones or have issues with the rhythm and meaning of different words. Individuals on the autistic spectrum may have restricted language abilities due to their poor attention skills, IQ, and comprehension abilities. While verbal children may not have speech articulation difficulties, they are generally limited in comparison to non-autistic children (Werker \& Byers-Heinlein, 2008).

A child on the autism spectrum may have their regular language development abilities restricted by this condition since it drastically alters the responses of the brain to different environmental stimuli. In normal people, the brain possesses the ability to detect different stimuli, patterns, and other similarities as well, thus making it easier for people to learn languages faster. However, autistic children are unable to detect stimuli or patterns and incapable of responding effectively. A reduced spoken language and word production skill in autistic children renders it difficult for them to perceive human speech, map different words, and comprehend information (Williams \& Minshew, 2010). Since language development delays are perhaps the most visible symptom of autism, it is important to understand the differences in development taking place between children in a monolingual and bilingual environment. It is also crucial to study the effect of bilingual environments on children with autism and their language development process since children in monolingual environments have been observed to suffer from impaired language acquisition and functioning skills. But studies conducted so far indicate that bilingual environments may be more advantageous for autistic children as it has a positive impact on their language acquisition abilities. However, other researchers argue that being exposed to bilingual environments may disrupt language development to a greater extent among autistic children (Dai, Burke, Naigles, Eigsti, \& Fein, 2018).

In light of this information, the present research seeks to compare the language development process in monolingual and bilingual children with ASD to ascertain how two different environments may impact this process. The following question is what this study is fundamentally trying to answer:

[1] How different are monolingual autistic children from bilingual ones in terms of the level of difficulty in their language development process?

\section{Literature Review}

Numerous studies have been conducted on ASD in order to understand its etiology and the impact it has on the social interactions of autistic children. Autism researchers have been studying social communication and language impairments for years now. Language development deficit has been widely acknowledged as one of autism's most observable symptoms. Therefore, researchers have also emphasized the importance of assessing speech disorders and early language deficits in children with ASD before they turn five (Hambly \& Fombonne, 2012; Mody \& Belliveau, 2013; Hampton, Rabagliati, Sorace, \& Fletcher-Watson, 2017).

\subsection{Autism Spectrum Disorder}

ASD happens to be a developmental disorder that affects an individual's language acquisition and development process, which are an integral part of an individual's social skills (Williams \& Minshew, 2010). Moreover, autism also causes social interaction and language deficits by restricting vocabulary and speaking abilities in autistic individuals, thus lessening their interest in social activities (Chen \& Kuo, 2017). The prevalence of autism varies widely in terms of gender since males have been observed to have four times greater chances of suffering from autism compared to females (Baio et al., 2018). The term 'Spectrum' may also be used while defining autism since affected individuals tend to have their comorbidities and impairment on a wide range in terms of skill deficits and symptoms. It may range from a mild case to a severe case with comprehension abilities, IQ levels, and verbal expressions varying widely between children affected by autism. Some may have impaired social interaction abilities whereas others may lack language and speech development abilities. However, an autism diagnosis is usually issued to those suffering from persistent social communication issues and challenges, restricted surroundings, and patterns in terms of behavior, repetitive behaviors and restricted sensory perception abilities as well (Luiselli, 2014). Children with ASD may differ in terms of difficulties experienced while improving their language skills, academic performance, and adaptive behaviors. While some may not even be able to form and complete a legible sentence, others may possess rich vocabulary that allows them to be a subject expert in a certain field (Weismer et al., 2010). Numerous studies that sought to understand the varying degrees to which autism affects an individual and the rich neurodiversity present in autistic subjects have confirmed the fact that early interventions could help autistic children in developing proficiency in certain subjects that could aid them in navigating adulthood with ease (Renty \& Roeyers, 2005; Fletcher-Watson, 2018; 
Houting, 2019). Individuals who were diagnosed early were found to perform better in terms of adaptation and communication compared to undiagnosed autistic children of the same age group (Sandbank et al., 2020).

\subsection{Language Development}

Language acquisition is undoubtedly one of the most interesting aspects of human development. It is a process that allows children to learn, communicate, and comprehend language right from an early age. Language development tends to take place rapidly during childhood when a child's language starts transitioning from incomprehensible babbles to structured sentences (Rudd \& Kelley, 2011). A child's social interactions also play a crucial role in boosting the ability of the child to understand language (Aslan \& Akyol, 2019). The language development process allows children to connect and understand different social contexts and the thoughts and ideas articulated by other people (Emen \& Aslan, 2019). Vygotsky (1980) concluded that the human mind has an incentive to be social since our early lives are completely dependent on having successful social interactions. In such cases, language is a bridge that allows people to interact with others and the environment in general. While language development skills may vary between children until the age of 5 , researchers have often stated that there are many perspectives on language development, and therefore, this process needs to be viewed holistically. Certain scholars study how language acquisition affects social development and human cognition by analyzing the age at which children start babbling or crying and the message they're trying to communicate with their peers (Bodrova \& Leong, 2006; Ermer, Guerin, Cosmides, Tooby, \& Miller, 2006). The slow development of language skills and the way these eventually give rise to legible words by the age of 18-24 months is often studied under intense scrutiny. Children continue to develop their language proficiency until the age of 8 , at which point they're capable of using the right grammatical structures and can distinguish between real and imaginary events (Dastpak, 2017). Research studies conducted on the language development process in children show that children in monolingual environments are capable of differentiating between languages but respond only when spoken to in their native language. However, Höhle, Bijeljac-Babic and Nazzi (2020) suggest that a child growing up in bilingual environments tend to focus on rhythmic structures - something that monolingual children completely miss out on. Compared to monolingual children, most bilingual infants also display statistically significant differences in grammar acquisition, early speech perception, and word learning (Byers-Heinlein et al., 2020).

\subsection{Stages of Language Development}

Children tend to experience the language development process in a fairly obvious sequence with a specific stage succeeding the previous one. However, the process tends to be independent of age since children go through the same stages at different age levels. Akmajian, Demers, Farmer and Harnish (1995) identified that children learning their native language tend to experience a set series of stages as they progress. The language development process includes the acquisition and development of certain abilities in a gradual manner, beginning from mere babbles and words to the construction of grammatically accurate sentences with the right verb inflections wherever necessary (Ball \& Lewis, 2014).

The first stage of language development occurs when infants are only able to hear and play with sounds. However, the only ways they respond are by babbling or cooing to the speaker. Only simple 'recognize and request' gestures elicit responses from children at this stage. By the age of 2-3 years, most children are capable of following two-part instructions (e.g., Get your food and go there), pointing to major body parts, toys and food, and clothing items when asked. They can converse 'three-word sentences', ask 'two-word questions', try multi-syllable words, take pleasure in challenge words, and have 50 to 70 percent of their verbal communication understood by foreigners. Their vocabulary also increases to $250-300$ words. They can also talk about present events and use regular plurals. Their listening abilities have also advanced enough to respond correctly to instructions. Any delays prevailing during this stage could result in difficulties interacting with their parents or failure to understand basic commands and gestures (Saxton, 2010).

By the age of 3-4 years, most children are capable of understanding an object's functions and are capable of understanding and asking 'why', 'what', 'who', 'when', and 'how' questions independently. Their listening abilities have also advanced enough to respond properly to three-part instructions. They can tell what others are doing. They can conjure sentences to describe an object's functions and the size of their vocabulary has also increased to 1500 words by this point. Similarly, their grammatical skills have also advanced well enough to be able to make use of complex structures like auxiliary, connectors, pronouns, and past participle. They can also identify positions, sizes, and quantities (Saxton, 2010).

Between ages 4-6, children become capable of understanding the concepts of length, size, positions, and the differences between these concepts. They become capable of listening to and following multi-step instructions. 
They can grasp the meaning of conversations between other people and enjoy increased attention spans. Additionally, their vocabulary grows richer with each passing day as well. They start using complex sentences, become imaginative while playing with others, and improve their writing abilities (Foster- Cohen, 2013).

By the time they turn 7 to 8 , their verbal grammatical skills have matured considerably. They can listen for a continuous period of time. The children are also able to distinguish between fantasy and reality and ask more detail-oriented why and how questions. The answers become comprehensible to them and they start asking further questions and seek clarifications as well. A failure to perform these activities may be seen in children who struggle with sorting things into complex or simple categories like fruits, animals, etc. Additionally, children with developmental delays may have difficulties in expressing their feelings, thoughts, and struggle with learning new information from others or following orders. Their social behavioral patterns are also restricted or limited to a considerable degree. Any developmental delays at this stage could result in difficulties while interacting with their peers or while following instructions or the inability to properly express their feelings and thoughts (Owens Jr, 1988).

Research studies analyzing the different language development stages have recognized that human development is virtually incomplete without a successful language acquisition phase. Researchers have time and again highlighted the relative ease with which children are able to learn languages and deploy them practically in a short span of time. It is as if humans were preprogrammed by their genes to acquire communication tools to live an active social life (McLaughlin, 2006). Certain researchers have attributed language learning to a biological predisposition for learning and acquiring language skills. Others attribute language development purely to the social environment one is born into (Fernandez \& Cairns, 2011).

\subsection{Previous Studies on Autism and Language Development/Impairment}

Language impairment is among the most commonly observed traits of ASD. Autism's impact on an individual's language development may vary widely, from mild non-verbal impairments to the adoption of an entirely unique language in which the children have to utilize echolalia and such tones for communication purposes (Mody \& Belliveau, 2013). Researchers have also studied ASD's impact on language development and association. These studies concluded that there were three primary deficits inherent to children with autism-delays in the early stages of language development where children continue in a holophrastic or babbling stage for a prolonged period of time, followed by the usage of an atypical language like echolalia and finally succeeded by pragmatic difficulties (Hudry et al., 2010). A study conducted on autistic children for understanding echolalia recognized its advantages in aiding communication, which permitted children with ASD to lower their cognitive load, thus helping them initiate and maintain a conversation with others while also helping them acquire actual language abilities. Other studies on echolalia showed that autistic children considered it to be a sign of progress in language development (Robert, 2014; David \& Weismer, 2014). Apart from this, Lund, Kohlmeier and Durán (2017) also conducted a systematic review of language development in autistic children raised in monolingual and bilingual environments where it was shown that there were only small differences between children growing up in both environments with regards to their expressive and receptive language. However, Gonzalez-Barrero and Nadig (2020) concluded that it was better for autistic children to grow up in a bilingual environment as it offered them a multidimensional perspective.

Seung, Siddiqi and Elder (2006) presented a case study regarding an autistic individual who had grown up in a bilingual environment and the response to the efficiency of intervention services. The study had a positive view on offering intervention services that were in the individual's native language along with a gradual, slow transition to another language. Bird et al. (2005) held a survey that questioned 48 parents/guardians of autistic children who were being raised in bilingual environments. It was observed that caregivers were being advised by most professionals to teach their child only a single language, even though multiple languages were being spoken in the child's environment.

In a more recent study, Mody and Belliveau (2013) consolidated the existing view that preverbal and verbal precursors of language development should be used as the foundation for studying the various brain and behavioral abnormalities linked to language development in children with ASD, thus providing appropriate pharmacological interventions for the effective treatment of ASD. Alike, Wilkinson et al. (2020) also carried out a longitudinal research study for studying the link between language development in autistic children ranging between 3-24 months of age and electroencephalogram. The conclusion drawn from the data was that language and electroencephalogram associations may take place differently, depending on brain mechanisms and risk status. Jouravlev et al. (2020) research reduced language lateralization in 28 people with ASD and concluded that it was a spatially selective and robust autism marker. Another study that analyzed verbal working memory revealed that a 
regular person who sees a letter tends to record and name it automatically even as their frontal working memory and left-hemisphere process it. On the other hand, autistic people tend to process similar information with their right hemisphere, thus failing to recode such information in a linguistic manner, making children unable to achieve proficiency in these language areas (Williams \& Minshew, 2010).

Certain studies that explore the language acquisition process in bilingual autistic children report that both monolingual and bilingual children possess similar language acquisition skills and had comparable expressive and receptive language abilities (Beauchamp \& MacLeod, 2017). On the other hand, researchers proved that most bilingual parents were reluctant to teach more than one language to their autistic children since they were finding it difficult to comprehend and understand multiple languages. As a result, they preferred teaching only the cultural relative language followed by the native language (Hammer et al., 2012). The Akabogu et al. (2020) clinical trial was a study that sought to understand the effects of language education intervention programs in over 86 participants, which was able to increase participation of autistic individuals in social gatherings. This result showed that language intervention was a useful tool for raising the social participation rates of autistic children. Another study involving 1615 autistic participants, which sought to study the efficiency of intervention programs, revealed that naturalistic, development and behavioral interventions had positive benefits for autistic children as well (Sandbank et al., 2020).

The studies mentioned above reveal some fascinating insights. Firstly, despite widespread presumptions that bilingual environments caused additional confusion to autistic children, the research studies reveal that there is no tangible evidence that conclusively proves the occurrence of language development delays due to added language input. Numerous studies conducted on autism have analyzed the bilingual language development process from a wide variety of language and developmental disorders (Down syndrome, speech impairment, developmental delays). The current studies exploring bilingual language development and autistic individuals show zero evidence that exposure to a second language can cause language development delays (Hambly \& Fombonne, 2012). However, it must be remembered that research in this field is relatively young. The actual results may vary, depending on the circumstances and severity of the ASD.

In conclusion, there are several studies that explore the language development process in autistic children and how they are affected when exposed to an environment where multiple languages are used regularly. However, these studies have only been conducted at the individual level on children who were either raised in monolingual or bilingual environments to ascertain the development of neurodevelopment conditions in such an environment. Little research has been conducted on the differences between autistic children in monolingual and bilingual environments and how they progress at each stage of language development. To fill these gaps, this study sought to compare monolingual and bilingual children on the basis of progress made at each stage of language development in order to understand how their environment has influenced their progress at specific stages of language acquisition.

\section{Methodology}

Children grow up in multilingual environments in numerous households across the world. But the research into the experiences of autistic children being raised in bilingual or monolingual environments and the variations in language development stages are yet to be comprehensively analyzed for an accurate conclusion. An answer to the research question that was stated earlier regarding the differences between children in certain language development domains while growing up in monolingual and bilingual environments was obtained by implementing a causal-comparative research design that involved over 201 monolingual and bilingual autistic children from over 49 nations across the globe. The research design was employed because it allows the investigation of many variables, which cannot be studied under regular experimental conditions.

\subsection{Participants}

Over 201 monolingual and bilingual autistic children from around 49 countries were involved in this study. The primary reason behind selecting participants from other countries around the world was to ensure that any differences in language development domains occurring in monolingual and bilingual environments were universal. Additionally, since the study was being researched in a primarily monolingual country, finding the children that fit the criteria of this study would have been a highly difficult task.

Out of all the participants, around 138 were males $(\mathrm{N}=138, \mathrm{M}=102.2, \mathrm{SD}=19.02) .63$ of them were females ( $\mathrm{N}$ $=63, \mathrm{M}=96.63, \mathrm{SD}=19.10$ ). Over 108 monolingual children participated in the study, including 39 females and 69 males whereas around 93 bilingual children took part in this study, including 24 females and 69 males. With an average age range of 5-8 years, this age range was selected since most studies in this area had primarily focused on autistic children who were still in their early stages. Therefore, the researcher decided to study more about different 
language milestones that were achieved during a late childhood period by children suffering from autistic disorder.

\subsection{Instrument}

For collecting the required data, a self-designed questionnaire was developed to serve the purpose of this study. The questionnaire included a demographic section that gathered information about the child's age, gender, nationality, and whether they were raised in a bilingual or monolingual environment. A second part contained six different domains, including listening, vocabulary, sentences, verbal grammar, general concepts, and questions formulation. These domains and their items were obtained from a language development stages chart created by "Kid Sense Child Development", which offered speech therapy and occupational therapy services to children suffering from developmental blocks in their behavior, attention, learning, language, speech, play, and movement. The chart had been designed to functionally screen developmental skills as per their age group. All information contained in the chart had been compiled over the course of years from different sources. It has been further refined by therapeutic consultation and clinical practice with school, child care, and pre-school teachers, which helped them understand the different developmental skills required for children to fulfill the various demands of educational environments in their area. Recently, the chart underwent further modifications after due consideration of the needs of the teachers and children. These domains were all selected for meeting the language development milestones of children between 5-8 years of age. Every language development stage's domains were deemed to have been achieved successfully by regular children. In case of a delay, problems would be reported accordingly. Children with ASD are likely to suffer from language development issues. Several important linguistic abilities were measured by the domain items listed on this questionnaire. In order to estimate the difficulty level of each domain and its items, a five-point Likert scale had been included, which offered the following responses (always, often, sometimes, rarely, and never). Selecting never indicated that the child found it extremely difficult whereas selecting always indicated an extremely low difficulty level. The validity and reliability of this questionnaire was put under intense scrutiny, which has been presented in the following section.

\subsection{Data Collection}

After designing the questionnaire, the researcher identified certain social media groups set up by the caregivers (parents or guardians) of children with ASD to gather the data necessary for this study. The group administrators were sent requests to permit the distribution of this questionnaire, which was duly allowed. Caregivers proceeded to send the completed questionnaire to the researcher, which was utilized by the researcher since caregivers can understand their children's condition better than others. In view of the fact that the survey happened to be distributed online, caregivers were capable of reading the questionnaire's requirements and completing the form accurately. All participating caregivers were requested to grant consent for the use of their data in this study. The information was sent over after they acknowledged their rights to withdraw from the study at their discretion and were convinced that their information would remain confidential.

\subsection{Validity and Reliability}

Any research instrument can be valid if it measures the features it is mainly designed to measure (Babbie, 2005). To establish the instrumentation's content validity, the judges' method was utilized. The panel members evaluated the instrumentation prior to the main study. They were three associate professors in the field of language acquisition. As there were six linguistic domains, the experts were asked to review and evaluate how suitable the items to each domain. The content validity index of conformity among judges was $89 \%$. According to Yusoff (2019), a minimum index of $80 \%$ deems to be acceptable. Based on the panel's comments and recommendations, the questionnaire was revised. A validity coefficient was also calculated as presented in Table 1 below.

To verify the reliability of the self-designed questionnaire, a Cronbach's alpha along with composite reliability were tested. A Cronbach's alpha value shows how accurately the responses to different items are in measuring the underlying construct. A Cronbach's alpha value of 70+ is considered good; an $80+$ value is considered better, and a $90+$ value is considered to be the best. Table 1 is a summary of the questionnaire domains' psychometric properties. As all values are above the acceptable limits, the consistency and interdependence between various items in questionnaire domains are considered to be high. The composite or construct reliability values in all six questionnaire domains are above 0.7 as well, thus showing that the responses to the items in the questionnaire groups are all reliable. The Average Variance Extracted (AVE) for all questionnaire domains also happens to be above 0.5 , which is enough for data consistency validation and interdependence purposes in this study. 
Table 1. Psychometric properties of the questionnaire

\begin{tabular}{llllll}
\hline Domains & Items No & Cronbach's alpha $(\alpha)$ & Composite Reliability & AVE & Validity coefficient \\
\hline Listening & 4 & 0.768 & 0.814 & 0.535 & 0.876 \\
Vocabulary & 3 & 0.718 & 0.746 & 0.766 & 0.847 \\
Sentences & 10 & 0.830 & 0.819 & 0.648 & 0.911 \\
Verbal Grammar & 9 & 0.873 & 0.749 & 0.604 & 0.934 \\
Question & 4 & 0.750 & 0.715 & 0.508 & 0.866 \\
General Concepts & 4 & 0.811 & 0.733 & 0.672 & 0.901 \\
\hline
\end{tabular}

\section{Analysis and Results}

To analyze the data collected for answering the main research question of this study, SPSS version 22 was employed. Means, standard deviations (std), range, and levels of difficulty were used as statistical methods of data analysis. Independent-samples t-tests were performed to conclude whether there are statistically significant differences or not. Table 2 shows that among 201 participants that took part in this study, the number of autistic monolingual males (64\% of the sample) are a bit higher than the number of females (36\% of the population). This trend was also seen in bilingual attributes where bilingual autistic males and females were $74 \%$ and $26 \%$ of the population respectively. Since most of the data was gathered from males than females in this sample, there could be a few data peculiarities, which cause wider data ranges and account for a higher standard deviation witnessed across by total deviation. As has been mentioned earlier, many studies assert that more males are autistic than females, which means that the male population tends to have a higher difficulty level compared to females. A reverse trend can be observed in the deviation from levels of difficulty data as well.

Table 2. Descriptive statistics of the sample

\begin{tabular}{|c|c|c|c|c|c|c|c|c|c|c|c|c|}
\hline \multirow[t]{2}{*}{ Autistic Children } & \multicolumn{3}{|c|}{ Number } & \multicolumn{3}{|c|}{ Percentage $(\%)$} & \multicolumn{3}{|l|}{ Mean } & \multicolumn{3}{|c|}{ Std. Dev } \\
\hline & Male & Female & Total & Male & Female & Total & Male & Female & Total & Male & Female & Total \\
\hline Monolinguals & 69 & 39 & 108 & 64 & 36 & 100 & 103.9 & 95.54 & 100.93 & 19.26 & 17.83 & 19.11 \\
\hline Bilinguals & 69 & 24 & 93 & 74 & 26 & 100 & 100.5 & 98.42 & 99.98 & 18.77 & 21.29 & 19.36 \\
\hline Total & 138 & 63 & 201 & 69 & 31 & 100 & 102.2 & 96.63 & 100.49 & 19.02 & 19.10 & 19.18 \\
\hline
\end{tabular}

Difficulty levels in every questionnaire domain have been statistically calculated in the following manner: (4.6 and above $)=5=$ very high; $(3.7-4.5)=4=$ high; $(2.8-3.6)=3=$ moderate; $(1.9-2.7)=2=$ low; $(1-1.8)=1=$ very low. As per Table 3, the listening domain displayed close relationships in all items as a result of the same range and low deviation. In spite of displaying significant standard deviation differences, both bilingual and monolingual autistic children experience high levels of difficulty in understanding multi-step directions and understanding longer and complicated sentences and suffered from poor vocabulary comprehension. When it came to understanding conversations between others, both groups experienced a moderate level of difficulty.

Table 3. Descriptive statistics of listening items

\begin{tabular}{lllllll}
\hline Listening Items & & Item 1 & Item 2 & Item 3 & Item 4 & Item 5 \\
\hline Monolingual autistic children & Mean & 3.8611 & 3.6600 & 3.0000 & 3.7667 & - \\
& Std. Deviation & 1.47177 & 1.36045 & 1.16811 & 1.37425 & - \\
& $\mathrm{N}$ & 108 & 108 & 108 & 108 & - \\
& Range & 4 & 4 & 4 & 4 & - \\
& Level of difficulty & High & High & Moderate & High & - \\
Bilingual autistic children & Mean & 3.9323 & 3.6577 & 2.8710 & 3.7183 & - \\
& Std. Deviation & 1.50192 & 1.36518 & 1.12507 & 1.36551 & - \\
& N & 93 & 93 & 93 & 93 & - \\
& Range & 4 & 4 & 4 & 4 & - \\
& Level of difficulty & High & High & Moderate & High & - \\
\hline
\end{tabular}

Note. Item 5 was removed from the listening domain due to its loading was less than $40 \%$.

Table 4 affirms that both bilingual and monolingual autistic children tend to experience a moderate level of difficulty when it comes to shape and color words (e.g., square, red) and while sorting different objects into sample categories (e.g., food, animals). This analysis also revealed that both groups of autistic children were less 
capable of classifying objects by specific traits (composition, use, color, form) since it had a high difficulty level.

Table 4. Descriptive statistics of vocabulary items

\begin{tabular}{lllll}
\hline Vocabulary Items & & Item 6 & Item 7 & Item 8 \\
\hline Monolingual autistic children & Mean & 2.9630 & 2.9630 & 3.7185 \\
& Std. Deviation & 1.25248 & 1.30367 & 1.39688 \\
& $\mathrm{~N}$ & 108 & 108 & 108 \\
& Range & 4 & 4 & 4 \\
& Level of difficulty & Moderate & Moderate & High \\
Bilingual autistic children & Mean & 2.9247 & 2.8495 & 3.7204 \\
& Std. Deviation & 1.27890 & 1.09292 & 1.41910 \\
& Range & 4 & 4 & 4 \\
& N & 93 & 93 & 93 \\
& Level of difficulty & Moderate & Moderate & High \\
\hline
\end{tabular}

Table 5 clearly demonstrates how difficult it is for autistic children to use imaginative language and complex sentences, which include giving or telling short oral reports, expressing opinions, acting out stories, pretending like they're someone else - all these activities were associated with a high difficulty level by both bilingual and monolingual autistic children. Both groups also reported moderate difficulty levels in understanding the use or function of objects, explaining their attributes, and using higher-level language to crack simple jokes, explain complex issues, talk about past events or movies in detail, argue their viewpoint, or engage in sarcastic remarks, or tease. Bilingual autistic children were able to explain the activities of other people better compared to monolingual children. Items 16 and 18 also recorded minor differences. In contrast to monolingual autistic children, bilingual children experienced only moderate levels of difficulty when it came to writing simple descriptive sentences and developing written language abilities. Bilingual autistic children also found it difficult to retell real and imaginary events compared to monolingual autistic children who rated it as moderately difficult.

Table 5. Descriptive statistics of sentence items

\begin{tabular}{|c|c|c|c|c|c|c|c|c|c|c|c|}
\hline \multicolumn{2}{|c|}{ Sentences Items } & \multirow{2}{*}{$\frac{\text { Item } 9}{2.6963}$} & \multirow{2}{*}{$\frac{\text { Item } 10}{2.7963}$} & \multirow{2}{*}{$\frac{\text { Item } 11}{3.8093}$} & \multirow{2}{*}{$\begin{array}{l}\text { Item } 12 \\
3.7278\end{array}$} & \multirow{2}{*}{$\frac{\text { Item13 }}{2.9074}$} & \multirow{2}{*}{$\frac{\text { Item14 }}{3.7963}$} & \multirow{2}{*}{$\frac{\text { Item15 }}{2.8611}$} & \multirow{2}{*}{$\begin{array}{l}\text { Item } 16 \\
3.7019\end{array}$} & \multirow{2}{*}{$\frac{\text { Item } 17}{3.6658}$} & \multirow{2}{*}{$\frac{\text { Item } 18}{2.8704}$} \\
\hline Monolingual & Mean & & & & & & & & & & \\
\hline autistic & Std. Deviation & 1.31166 & 1.16618 & 1.55601 & 1.43942 & 1.23453 & 1.48804 & 1.13119 & 1.35763 & 1.34790 & 1.19260 \\
\hline children & $\mathrm{N}$ & 108 & 108 & 108 & 108 & 108 & 108 & 108 & 108 & 108 & 108 \\
\hline \multirow{7}{*}{$\begin{array}{l}\text { Bilingual } \\
\text { autistic } \\
\text { children }\end{array}$} & Range & 4 & 4 & 4 & 4 & 4 & 4 & 4 & 4 & 4 & 4 \\
\hline & $\begin{array}{l}\text { Level of } \\
\text { difficulty }\end{array}$ & Moderate & Moderate & High & High & Moderate & High & Moderate & High & High & Moderate \\
\hline & Mean & 2.4194 & 2.8495 & 3.8711 & 3.8710 & 2.7512 & 3.8280 & 2.9140 & 2.8925 & 3.8817 & 3.9247 \\
\hline & Std. Deviation & 1.27963 & 1.18822 & 1.57434 & 1.50890 & 1.28095 & 1.37606 & 1.23935 & 1.27230 & 1.49196 & 1.62684 \\
\hline & $\mathrm{N}$ & 93 & 93 & 93 & 93 & 93 & 93 & 93 & 93 & 93 & 93 \\
\hline & Range & 4 & 4 & 4 & 4 & 4 & 4 & 4 & 4 & 4 & 4 \\
\hline & $\begin{array}{l}\text { Level of } \\
\text { difficulty }\end{array}$ & Low & Moderate & High & High & Moderate & High & Moderate & Moderate & High & High \\
\hline
\end{tabular}

Table 6 shows that both bilingual and monolingual experienced high difficulty levels in utilizing appropriate grammar structures in their speeches. Both groups also experienced high difficulty levels while talking about events set in the past and future, using different adjectives, adverbs, and pronouns, and prepositions in the right manner. Additionally, both of them also suffered from moderate difficulty levels while using helping and main verbs, indefinite and definite articles in the right manner, and were severely limited in being able to differentiate between irregular and regular verbs. This domain's analysis does yield a minor difference between the two groups - bilingual autistic children experienced low difficulty levels when it came to using connectors and words that added new information or continued an idea compared to their monolingual counterparts. Although no statistically tangible differences were observed, bilingual autistic children performed better than monolingual children when it came to verbal grammar skills. 
Table 6. Descriptive statistics of verbal grammar items

\begin{tabular}{|c|c|c|c|c|c|c|c|c|c|c|}
\hline \multicolumn{2}{|c|}{ Verbal Grammar Items } & \multirow{2}{*}{\begin{tabular}{|l|} 
Item19 \\
3.9093
\end{tabular}} & \multirow{2}{*}{$\begin{array}{l}\text { Item20 } \\
3.7556\end{array}$} & \multirow{2}{*}{$\begin{array}{l}\text { Item } 21 \\
2.8519\end{array}$} & \multirow{2}{*}{$\begin{array}{l}\text { Item } 22 \\
3.8037\end{array}$} & \multirow{2}{*}{$\begin{array}{l}\text { Item } 23 \\
2.8130\end{array}$} & \multirow{2}{*}{$\frac{\text { Item24 }}{3.9259}$} & \multirow{2}{*}{\begin{tabular}{|l|} 
Item25 \\
2.8241
\end{tabular}} & \multirow{2}{*}{$\begin{array}{l}\text { Item } 26 \\
2.7963\end{array}$} & \multirow{2}{*}{$\begin{array}{l}\text { Item } 27 \\
4.7378\end{array}$} \\
\hline Monolingual & Mean & & & & & & & & & \\
\hline autistic & Std. Deviation & 1.52196 & 1.34663 & 1.25910 & 1.47998 & 1.31016 & 1.53488 & 1.26660 & 1.25868 & 1.67032 \\
\hline children & $\mathrm{N}$ & 108 & 108 & 108 & 108 & 108 & 108 & 108 & 108 & 108 \\
\hline \multirow{7}{*}{$\begin{array}{l}\text { Bilingual } \\
\text { autistic } \\
\text { children }\end{array}$} & Range & 4 & 4 & 4 & 4 & 4 & 4 & 4 & 4 & 4 \\
\hline & Level of difficulty & High & High & Moderate & High & Moderate & High & Moderate & Moderate & Very high \\
\hline & Mean & 3.8032 & 3.9462 & 2.9570 & 3.9613 & 3.0215 & 3.8677 & 2.9462 & 2.7419 & 4.6427 \\
\hline & Std. Deviation & 1.48532 & 1.51556 & 1.23283 & 1.42732 & 1.22455 & 1.47447 & 1.19205 & 1.19695 & 1.59470 \\
\hline & $\mathrm{N}$ & 93 & 93 & 93 & 93 & 93 & 93 & 93 & 93 & 93 \\
\hline & Range & 4 & 4 & 4 & 4 & 4 & 4 & 4 & 4 & 4 \\
\hline & Level of difficulty & High & High & Moderate & High & Moderate & High & Moderate & Low & Very high \\
\hline
\end{tabular}

Table 7 shows that general concept items were considered to be of a moderate difficulty level by both monolingual and bilingual autistic children. This moderate difficulty level was also seen in their ability to use positions properly (for instance, words like corner, in a line, in front, last, beside/next to, through, between, away from, around, middle) and comprehend concepts around size like thin, fat, tall, and short. They were also slow to understand quantity concepts and distinguish between fantasy and reality.

Table 7. Descriptive statistics of general concept items

\begin{tabular}{llllll}
\hline General Concept Items & & Item 28 & Item 29 & Item 30 & Item 31 \\
\hline Monolingual autistic & Mean & 3.0556 & 2.9722 & 2.8056 & 2.9352 \\
children & Std. Deviation & 1.22156 & 1.37710 & 1.08048 & 1.24760 \\
& $\mathrm{~N}$ & 108 & 108 & 108 & 108 \\
& Range & 4 & 4 & 4 & 4 \\
Bilingual autistic & Level of difficulty & Moderate & Moderate & Moderate & Moderate \\
children & Mean & 3.0645 & 2.9140 & 2.8387 & 3.0108 \\
& Std. Deviation & 1.33357 & 1.25677 & 1.18221 & 1.28109 \\
& N & 93 & 93 & 93 & 93 \\
& Range & 4 & 4 & 4 & 4 \\
& Level of difficulty & Moderate & Moderate & Moderate & Moderate \\
\hline
\end{tabular}

Table 8 reveals that both monolingual and bilingual autistic children have similar difficulty levels in all items in this domain. They experienced moderate difficulty in understanding who questions whereas they were able to ask how, where, when, why, and what questions with high difficulty. Giving explanations, providing solutions, justifying decisions, and making predictions were highly difficult as well. However, asking more questions for clarification purposes was rated as being extremely difficult by members of both groups.

Table 8. Descriptive statistics of question items

\begin{tabular}{llllll}
\hline Question Items & & Item 32 & Item 33 & Item 34 & Item 35 \\
\hline Monolingual autistic & Mean & 2.7963 & 3.7667 & 3.6759 & 4.5770 \\
children & Std. Deviation & 1.24375 & 1.36786 & 1.30080 & 1.48736 \\
& $\mathrm{~N}$ & 108 & 108 & 108 & 108 \\
& Range & 4 & 4 & 4 & 4 \\
\multirow{3}{*}{$\begin{array}{l}\text { Bilingual autistic } \\
\text { children }\end{array}$} & Level of difficulty & Moderate & High & High & Very high \\
& Mean & 2.7654 & 3.6699 & 3.7731 & 4.6131 \\
& Std. Deviation & 1.34648 & 1.03628 & 1.36648 & 1.34753 \\
& $\mathrm{~N}$ & 93 & 93 & 93 & 93 \\
& Range & 4 & 4 & 4 & 4 \\
& Level of difficulty & Moderate & High & High & Very high \\
\hline
\end{tabular}

In conclusion, Table 9 offers the general descriptive statistics of members from both groups in the questionnaire domains. It is concluded based on these results that all autistic children tend to experience the same language development difficulties, irrespective of whether they were being raised in a monolingual or bilingual environment. Difficulty levels ranged between moderate-high for the items on this questionnaire. Items like 
verbal grammar, sentence construction, listening comprehension, and other related concepts had a high difficulty level attached to them whereas questions formulation and vocabulary had a moderate difficulty level attached to them by both groups. Using a t-test, the table also reveals that the groups have no major statistically tangible difference between them in the items listed here.

Table 9. Overall descriptive statistics of questionnaire groups

\begin{tabular}{llllllll}
\hline Questionnaire groups & Listening & Vocabulary & Sentences & Verbal Grammar & Questions & Concepts \\
\hline Monolingual & Mean & 11.9794 & 8.5370 & 38.5185 & 33.6019 & 11.6481 & 16.7593 \\
autistic children & Std. Deviation & 3.40377 & 3.04614 & 8.22860 & 8.11476 & 3.97731 & 3.93610 \\
& $\mathrm{~N}$ & 4 & 3 & 10 & 9 & 4 & 4 \\
& Range & 16 & 12 & 39 & 36 & 16 & 16 \\
& Level of difficulty & High & Moderate & High & High & Moderate & High \\
Bilingual autistic & Mean & 12.0538 & 8.4956 & 39.2796 & 36.6989 & 11.6452 & 16.2151 \\
children & Std. Deviation & 3.75142 & 2.95849 & 8.72075 & 8.03631 & 3.59542 & 3.81886 \\
& $\mathrm{~N}$ & 4 & 3 & 10 & 9 & 4 & 4 \\
& Range & 16 & 12 & 39 & 34 & 16 & 16 \\
Total & Level of difficulty & High & Moderate & High & High & Moderate & High \\
& T & .217 & .100 & .636 & .085 & .006 & .991 \\
& df & 199 & 199 & 199 & 199 & 199 & 199 \\
\hline
\end{tabular}

\section{Discussion}

How different are monolingual autistic children from bilingual ones in terms of the level of difficulty in their language development process?

The current study compared two groups of autistic children who are being raised in monolingual and bilingual environments respectively, to discover whether their linguistic environments had any bearing on their progress in language development. Here in this research study, both monolingual and bilingual groups were matched systematically based on their age. The monolingual and bilingual groups included children who were raised with exposure to different first and second languages as well. It is a known fact that certain language pairings tend to cause different language outcomes as certain languages make use of the same syntactic and semantic structures whereas others do not (Werker \& Byers-Heinlein, 2008). The results displayed in the preceding section have confirmed the fact that both monolingual and bilingual children suffer from clear problems with regard to language development abilities. However, both groups also had a similar amount of difficulty ranging between moderate and high in six important language development domains that evaluated their usage of verbal grammar, questioning, general language concepts, crafting of sentences, vocabulary, and listening abilities. The overall results also confirmed that while both monolingual and bilingual autistic children experienced the same high level of difficulty when it came to verbal grammar, sentence construction, comprehension, listening, and other important concepts, they reported only a moderate difficulty level when it came to crafting questions and increasing the depth of their vocabulary.

Additionally, certain subtle differences were also observed between the two groups within the different items listed on all six domains. For instance, when it came to sentences, bilingual autistic children were more capable of understanding what others were doing and developing comprehensive written language abilities, including the ability to pen descriptive stories and different kinds of sentences compared to monolingual children. On the other hand, monolingual autistic children were found to perform better compared to bilingual children when it came to verbal grammar, such as in the utilization of connectors and words, which offer more information about an idea. However, these differences were deemed to be not statistically significant enough to draw a conclusion.

It is important to mention that the language development process starts right from birth for all children. It receives a boost when they start playing and interacting with others. As mentioned earlier that language cannot be acquired in isolation. This means that social interaction affects human communication, and particularly, language acquisition. Research certainly conducted with children demonstrates that acquiring any language is subject to the extent of interaction with a caregiver. Put simply, there is substantial evidence that social interaction has a crucial part in language acquisition (Aslan \& Akyol, 2019). However, autistic children find it more difficult to learn and make use of language at the same pace as that of normal children because they tend to be less social than their characteristically developing peers. Another possible explanation for these results may be attributable to the reason that most research studies conducted on children exploring their language 
development process have demonstrated that both monolingual and bilingual children tend to achieve the same language learning milestones at similar age levels (Fennell, Byers-Heinlein, \& Werker, 2007; Oller, Eilers, Urbano, \& Cobo-Lewis, 1997). The reason why both autistic groups record similar difficulty levels could be because autistic children, in general, tend to display low-interest levels in interacting with others during the first few years of their life, irrespective of the number of languages they are exposed to. They are typically more interested in the things that take place around them. Since they are uninterested in interacting with others at the same rate as regular, there are not many chances for them to enhance their language development skills. The language milestones for both monolingual and bilingual children are achieved at around the same age ranges, even though bilingual children have to learn an entirely different vocabulary, grammar, etc. as well.

While bilingual children do face some delays compared to monolingual autistic children, the delays are not permanent or tangible enough to make a noticeable difference to their language acquisition process (sequential and simultaneous). Monolingual and bilingual children use language for their purposes at roughly the same developmental milestones (Genesee, Paradis, \& Crago, 2004). The findings here affirm the conclusions drawn by Hambly and Fombonne (2012), as well as Beauchamp and MacLeod (2017) in which no significant differences were found between bi/trilingual and monolingual autistic children when tested on the same indices, thus meaning that learning an extra language didn't aggravate language development issues in autistic individuals. The current study also confirms the findings of Paradis (2007), which concluded that monolingual and bilingual children performed at similar levels when it came to deploying grammatical patterns and rates. Although these studies are not without a few inconsistencies, the overwhelming evidence confirms that dual-language input is not a language development barrier for autistic individuals.

This shows that being exposed to a bilingual environment is not something that delays language development in young children with ASD. Monolingualism and bilingualism are not detrimental nor do they cause any language delays in children with autistic issues. Bilingualism does not cause any confusion or have an inherently negative effect on development. When children are acquiring basic proficiency skills in a second language, that does not come at the cost of first language at all. This study's conclusion is great news for many families that speak more than one language at home who have been advised to restrict their usage of a native language to ease the language input for their autistic children.

\section{Limitations}

It is extremely crucial to acknowledge the limitations of this study as well. There are two main limitations related to this study. Firstly, this was actually an exploratory study that sought to compare the general impact of monolingual and bilingual exposure among young children suffering from ASD. This was not a true experiment. Zero variables were being manipulated in a systematic manner, which means that no casual relationships were established.

The study's second limitation happens to be applicable to all published research studies on autism, monolingualism, and bilingualism that have been conducted to date - the study's sample size, which might have limited the researcher's ability to detect actual differences between both groups. For detecting statistically significant differences, it could be that a larger sample size might have been needed. Thus, studies with larger sample size and longitudinal studies of monolingual and bilingual children with ASD are the need of the hour for elaborating the effects of exposure to bilingual environments over a longer period of time. Moreover, further research studies also have to be conducted to determine the ideal language to be used in autism therapy.

Future studies must not only be conducted on monolingual or bilingual autistic children, but also on multilingual children. Although longitudinal research studies are more time-consuming, it tends to be more accurate in determining whether linguistic environments have an impact on language development delays. Another great research idea would be an exploration of whether there's a significant difference between genders and the linguistic environments they are raised in.

\section{Conclusion}

This study compared monolingual and bilingual children with ASD in order to determine whether there were any statistically significant differences between them when it came to language development abilities. The study's general conclusion was that both groups of autistic children tend to achieve language development milestones at the same age with similar levels of difficulty, irrespective of the linguistic environment they have been raised in. The difficulty levels between the two groups ranged between moderate to high in all six language development domains whereas a high difficulty level was observed in domains like verbal grammar, sentence construction, and listening comprehension. Moderate difficulty levels were reported in domains like question formulation and vocabulary by both groups of autistic children. The study's findings reveal that there are no statistically tangible 
differences between both groups in any language domain, although some inconsequential differences were indeed observed in the verbal grammar and sentence construction domains.

\section{References}

Akabogu, J., Nnamani, A., Otu, M. S., Uloh-Bethels, A. C., Ukoha, E., Iyekekpolor, O. M., \& Ike, C. V. (2020). Effects of a language education intervention on social participation among emerging adults with autism. Journal of International Medical Research, 48(1), 1-6. https://doi.org/10.1177/0300060519839510

Akmajian, A., Demers, R., Farmer, A., \& Harnish, R. (1995). Linguistics: An Introduction to Language and Communication. The MIT Press.

Aslan, D., \& Akyol, A. (2019). Impact of an empathy training program on children's perspective-taking abilities. Psychological Reports. https://doi.org/10.1177/0033294119868785

Babbie, E. (2005). The basic of social research. Canada: Wadsworth Publishing Company.

Baio, J., Wiggins, L., Christensen, D. L., et al. (2018). Prevalence of autism spectrum disorder among children aged 8 years-Autism and developmental disabilities monitoring Network, 11 Sites, United States, 2014. MMWR Surveill Summ, 67(SS-6), 1-23. https://doi.org/10.15585/mmwr.mm6745a7

Ball, J., \& Lewis, M. (2014). First Nations Elders' and Parents' Views on Supporting their Children's Language Development. Canadian Journal of Speech-Language Pathology \& Audiology, 38(2), 224-237.

Beauchamp, M. L., \& MacLeod, A. A. (2017). Bilingualism in children with autism spectrum disorder: Making evidence-based recommendations. Canadian Psychology, 58(3), 250-262. https://doi.org/10.1037/cap0000122

Bird, E. K., Cleave, P., Trudeau, N., Thordardottir, E., Sutton, A., \& Thorpe, A. (2005). The language abilities of bilingual children with Down syndrome. American Journal of Speech-Language Pathology, 14(3), 187-199. https://doi.org/10.1044/1058-0360(2005/019)

Bodrova, E., \& Leong, D. (2006). Tools of the mind the Vygotskian approach to early childhood education. New Jersey: Pearson/Merrill Prentice Hall.

Byers-Heinlein, K., Tsui, R. K. Y., Soderstrom, M., Fennell, C., Gonzalez-Gomez, N., \& Singh, L. (2020). The Development of Gaze Following in Monolingual and Bilingual Infants: A Multi-Lab Study. https://doi.org/10.31234/osf.io/sgfhv

Chen, Z., \& Kuo, L. (2017). Language and literacy development among children with Autism spectrum. Journal of Childhood and Developmental Disorder, 3(3), 1-4. https://doi.org/10.4172/2472-1786.100052

Dai, Y. G., Burke, J. D., Naigles, L., Eigsti, I. M., \& Fein, D. A. (2018). Language abilities in monolingual- and bilingual-exposed children with Autism or other developmental disorders. Research in Autism Spectrum Disorders, 55, 38-49. https://doi.org/10.1016/j.rasd.2018.08.001

Dastpak, M. F. (2017). A comparative study on the Vyygotsky's perspective on child language development with nativism and behvaiorism. International Journal of Languages' Education and Teaching, 5(2), 230-238. https://doi.org/10.18298/ijlet.1748

David, M. M., \& Weismer, S. E. (2014). Characterization and prediction of early reading abilities in children on the autism spectrum. Journal of Autism Developmental Disorder, 44(1), 828-845. https://doi.org/10.1007/s10803-013-1936-2

Emen, M., \& Aslan, D. (2019). The Relationship between Perspective Taking Skills and Language Development in Preschool Children. Journal of Education and Educational Development, 6(1), 25-42. https://doi.org/10.22555/joeed.v6i1.2159

Ermer, E., Guerin, S. A., Cosmides, L., Tooby, J., \& Miller, M. B. (2006). Theory of mind broad and narrow: Reasoning about social exchange engages ToM areas, precautionary reasoning does not. Social Neuroscience, 1(3-4), 196-219. https://doi.org/10.1080/17470910600989771

Fennell, C. T., Byers-Heinlein, K., \& Werker, J. F. (2007). Using speech sounds to guide word learning: The case of bilingual infants. Child Development, 78(5), 1510-1525. https://doi.org/10.1111/j.1467-8624.2007.01080.x

Fernandez, E. M., \& Cairns, H. (2011). Fundamentals of psycholinguistics. UK: Wiley-Blackwell Publication.

Foster-Cohen, S. (2013). An introduction to child language development. Routledge Taylor \& Francis group. https://doi.org/10.4324/9781315844893 
Genesee, F., Paradis, J., \& Crago, M. (2004). Dual language development and disorders: A handbook on bilingualism and second language learning. Baltimore, MD: Paul H Brookes Publishing Co.

Gonzalez-Barrero, A. M., \& Nadig, A. (2020). Bilingualism and language development in children with autism spectrum disorders. In F. Volkmar (Ed.), Encyclopedia of autism spectrum disorders. New York, NY: Springer. https://doi.org/10.1007/978-1-4614-6435-8_102508-1

Hambly, C., \& Fombonne, E. (2012). The impact of bilingual environments on language development in children with autism spectrum disorders. Journal of Autism and Developmental Disorders, 42(7), 1342-1352. https://doi.org/10.1007/s10803-011-1365-z

Hammer, C. S., Komaroff, E., Rodriguez, B. L., Lopez, L. M., Scarpino, S. E., \& Goldstein, B. (2012). Predicting Spanish-English bilingual children's language abilities. Journal of Speech, Language, and Hearing Research, 55(5), 1251-1264. https://doi.org/10.1044/1092-4388(2012/11-0016)

Hampton, S., Rabagliati, H., Sorace, A., \& Fletcher-Watson, S. (2017). Autism and bilingualism: A qualitative interview study of parents' perspectives and experiences. Journal of Speech, Language, and Hearing Research, 60(2), 435-446. https://doi.org/10.1044/2016_JSLHR-L-15-0348

Höhle, B., Bijeljac-Babic, R., \& Nazzi, T. (2020). Variability and stability in early language acquisition: Comparing monolingual and bilingual infants' speech perception and word recognition. Bilingualism: Language and Cognition, 23(1), 56-71. https://doi.org/10.1017/S1366728919000348

Houting, J. (2019). Neurodiversity: An insider's perspective. Autism, 23(2), 271-273. https://doi.org/10.1177/1362361318820762

Hudry, K., Leadbitter, K., Temple, K., Slonims, V., McConachie, H., Aldred, C., ... Consortium, P. (2010). Preschoolers with autism show greater impairment in receptive compared with expressive language abilities International Journal of language and Communication Disorder, 45, 681-690. https://doi.org/10.3109/13682820903461493

Jouravlev, O., Kell, A., Mineroff, Z., Haskins, A., Ayyash, D., Kanwisher, N., \& Fedorenko, E. (2020). Reduced language lateralization in autism and the broader autism phenotype as assessed with robust individual-subjects analyses. bioRxiv. https://doi.org/10.1101/2020.02.10.942698

Luiselli, J. K. (2014). Children and youth with autism spectrum disorder (ASD): Recent advances and innovations in assessment, education, and intervention. Oxford: Oxford University Press. https://doi.org/10.1093/med:psych/9780199941575.001.0001

Lund, E. M., Kohlmeier, T. L., \& Durán, L. K. (2017). Comparative language development in bilingual and monolingual children with autism spectrum disorder: A systematic review. Journal of Early Intervention, 39(2), 106-124. https://doi.org/10.1177/1053815117690871

Maenner, M. J., Shaw, K. A., Baio, J., et al. (2020). Prevalence of Autism Spectrum Disorder Among Children Aged 8 Years-Autism and Developmental Disabilities Monitoring Network, 11 Sites, United States, 2016. MMWR Surveill Summ, 69(4), 1-12. https://doi.org/10.15585/mmwr.ss6904a1

McLaughlin, S. F. (2006). Introduction to language development (2nd ed.). Clifton Park, NY: Delmar Cengage Learning.

Mody, M., \& Belliveau, J. W. (2013). Speech and language impairments in Autism: insights from behavior and neuroimaging. North American Journal of Medicine \& Science, 5(3), 157-161. https://doi.org/10.7156/v5i3p157

Oller, D. K., Eilers, R. E., Urbano, R., \& Cobo-Lewis, A. B. (1997). Development of precursors to speech in infants exposed to two languages. Journal of Child Language, 24(2), 407-426. https://doi.org/10.1017/S0305000997003097

Owens Jr., R. (1988). Language Development: An Introduction (2nd ed., vol. 1, pp. 199-387). Geneseo: Merrill Publishing Company.

Paradis, J. (2007). Bilingual children with specific language impairment: Theoretical and applied issues. Applied Psycholinguistics, 28(3), 551-564. https://doi.org/10.1017/S0142716407070300

Posar, A., Resca, F., \& Visconti, P. (2015). Autism according to diagnostic and statistical manual of mental disorders 5th edition: The need for further improvements. Journal of Pediatric Neurosciences, 10(2), 146-148. https://doi.org/10.4103/1817-1745.159195 
Renty, J., \& Roeyers, H. (2013). Students with autism spectrum disorder in special and general education schools in flanders. The British Journal of Development Disabilities, 51(100), 27-39. https://doi.org/10.1179/096979505799103795

Robert, J. M. (2014). Echolalia and language development in children with ASD. Communicating Autism, 11, 55-74. https://doi.org/10.1007/s40489-015-0067-4

Rudd, L. C., \& Kelley, H. M. (2011). Language Development. In S. Goldstein \& J. A. Naglieri (Eds.), Encyclopedia of Child Behavior and Development. Springer, Boston, MA. https://doi.org/10.1007/978-0-387-79061-9_1609

Sandbank, M., Bottema-Beutel, K., Crowley, S., et al. (2020). Project AIM: Autism intervention meta-analysis for studies of young children. Psychol Bull, 146(1), 1-29. https://doi.org/10.1037/bul0000215

Sandbank, M., Woynaroski, T., Watson, L. R., Gardner, E., Kaysili, B. K., \& Yoder, P. (2017). Predicting intentional communication in preverbal preschoolers with autism spectrum disorder. Journal of Autism and Developmental Disorders, 47(6), 1581-1594. https://doi.org/10.1007/s10803-017-3052-1

Saxton, M. (2010). Child Language: Acquisition and Development. Thousand Oaks, CA: SAGE.

Seung, H., Siddiqi, S., \& Elder, J. H. (2006). Intervention outcomes of a bilingual child with autism. Journal of Medical Speech-Language Pathology, 14, 53-63.

Vahia, V. N. (2013). Diagnostic and statistical manual of mental disorders 5: A quick glance. Indian Journal of Psychiatry, 55(3), 220-223. https://doi.org/10.4103/0019-5545.117131

Vygotsky, L. S. (1980). Mind in society: The development of higher psychological processes. Harvard University Press. https://doi.org/10.2307/j.ctvjf9vz4

Weismer, S. E., Lord, C., \& Esler, A. (2010). Early language patterns of toddlers on the autism spectrum compared to toddlers with developmental delay. Journal of Autism and Developmental Disorders, 40(10), 1259-1273. https://doi.org/10.1007/s10803-010-0983-1

Wilkinson, C. L., GabardDurnam, L. J., Kapur, K., TagerFlusberg, H., Levin, A. R., \& Nelson, C. A. (2020). Use of longitudinal EEG measures in estimating language development in infants with and without familial risk for autism spectrum disorder. Neurobiology of Language, 1(1), 33-53. https://doi.org/10.1162/nol_a_00002

Williams, L. D., \& Minshew, J. N. (2010). How the brain thinks in Autism: implications for language intervention. The Asia Leader, 15(5), 8-11. https://doi.org/10.1044/leader.FTR1.15052010.8

Werker, J. F., \& Byers-Heinlein, K. (2008). Bilingualism in infancy: First steps in perception and comprehension. Trends in Cognitive Sciences, 12(4), 144-151. https://doi.org/10.1016/j.tics.2008.01.008

Yusoff, M. S. B. (2019). ABC of content validation and content validity index calculation. Education in Medicine Journal, 11(2), 49-54. https://doi.org/10.21315/eimj2019.11.2.6

\section{Copyrights}

Copyright for this article is retained by the author, with first publication rights granted to the journal.

This is an open-access article distributed under the terms and conditions of the Creative Commons Attribution license (http://creativecommons.org/licenses/by/4.0/). 